\title{
NUMERICAL SIMULATION AND EXPERIMENTAL VALIDATION OF GAP SUPPORTED TUBE SUBJECTED TO FLUID-ELASTIC COUPLING FORCES FOR HYBRID CHARACTERIZATION TESTS
}

\author{
Wissam BENMALEK \\ EDF \& CNRS FEMTO-ST Institute \\ Clamart, France
}

\author{
Manuel COLLET \\ CNRS FEMTO-ST Institute \\ Besançon, France
}

\author{
Emmanuel FOLTETE \\ CNRS FEMTO-ST Institute \\ Besançon, France
}

\author{
Morvan OUISSE \\ CNRS FEMTO-ST Institute \\ Besançon, France
}

\author{
Mathieu CORUS \\ EDF \\ Clamart, France
}

\begin{abstract}
Steam Generator (SG) tubes are subjected to fluid-elastic coupling forces and impacts against support plates \& antivibration bars. Understanding their vibrations is crucial not only at the design stage, but also to optimize the SG maintenance policy and to lengthen the SG service life. The aim of our research is to provide a better understanding of the conjugate stabilizing effects of impacts and coupling with fluidelastic forces. Since fluid-elastic forces are difficult to simulate and expensive to reproduce experimentally, the fluid coupling forces of our numerical model are represented using velocity dependent damping and stiffness matrices, both for the fluid and the tube. Their effect is experimentally reproduced having recourse to active vibration control in the frame of specifically designed "hybrid" experimental tests. In this paper, we present a method for modeling tube vibrations in order to estimate the conjugate effects of the coupling between the fluid elastic forces and impacts. This strategy lowers the costs and avoids the difficulties associated to the case of fluid in the experiments. Our numerical model will be implemented in the active control loop in the next step of the study.
\end{abstract}

\section{NOMENCALTURE}

b : Influence vector

C : Structural damping Matrix

$C_{d} \quad$ : Dimentionless damping coupling coefficient

$\mathrm{C}_{\mathrm{f}} \quad$ : Added fluid damping Matrix

$\mathrm{C}_{\mathrm{k}} \quad$ : Dimensionless stiffness coupling coefficient

D : Tube diameter

Ec : Kinetic energy

Em : Mechanical energy

$\begin{array}{ll}E p & : \text { Potential energy } \\ E p c & : \text { Impact potential energy } \\ \mathrm{F}_{\mathrm{c}} & : \text { Impact force } \\ \mathrm{F}_{\mathrm{fe}} & : \text { Fluid elastic force } \\ \mathrm{F}_{T} & : \text { Turbulence force } \\ f & : \text { Frequency vibration } \\ f & : \text { Rice frequency } \\ g & : \text { Gap distance } \\ \mathcal{K} & : \text { Structural stiffness matrix } \\ \mathrm{K}_{\mathrm{c}} & : \text { Impact stiffness } \\ \mathrm{K}_{\mathrm{f}} & : \text { Added fluid stiffness } \\ k_{\mathrm{f}} & : \text { Modal added fluid stiffness } \\ \mathcal{M} & : \text { Structural mass matrix } \\ \mathrm{M}_{\mathrm{c}} & : \text { Mass Impact } \\ \mathrm{M}_{f} & : \text { Added fluid mass } \\ m_{\mathrm{f}} & : \text { Modal added fluid mass } \\ q & : \text { Generalized modal coordinates } \\ \mathrm{T}_{\mathrm{c}} & : \text { Impact duration } \\ t & : \text { Time } \\ V & : \text { Fluid velocity } \\ V_{r} & : \text { Dimensionless reduced fluid velocity } \\ x & : \text { Coordinate gap impact } \\ \rho_{f} & : \text { Mass density of the fluid } \\ \sigma & : \text { RMS value } \\ \omega & : \text { Modal circular frequency (mode } \mathrm{n} \text { ) } \\ \zeta & : \text { Modal damping (mode } \mathrm{n} \text { ) } \\ \varphi & : \text { Eigenvector (mode } \mathrm{n}) \\ \phi & : \text { Eigenvector matrix } \\ (*) & : \text { Mode } \mathrm{n} \\ (*)_{(n)} & : \text { Iteration } \mathrm{n} \\ (*) & : \text { Stagnant water }(V=0) \\ & \end{array}$




\section{INTRODUCTION}

Steam generators are heat exchangers used to convert water into steam from heat produced in a nuclear reactor core. They are used in pressurized water reactors between the primary and secondary coolant loops.

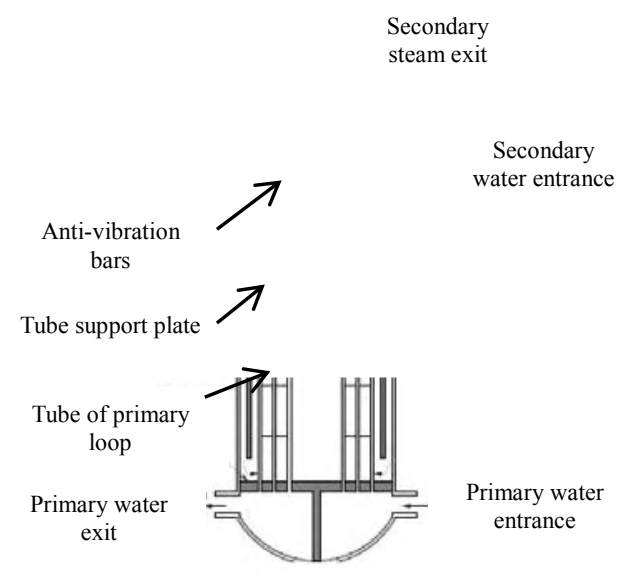

Figure 1. Steam generator

When the steam generator is operating, water in the secondary loop partially changes to steam. When rising up, this fluid interacts with the U-tubes (see Fig.1), which are therefore subjected to flow excitation.

This excitation can be split into two kind of forces: turbulence forces which are independent of the movement of the tube and the so-called fluid-elastic coupling forces, depending on acceleration, velocity, displacement and fluid reduced velocity[1][2]\&[3]. The total flow excitation can be finally expressed as:

$$
\begin{gathered}
F_{T}+F_{f-e}(\ddot{y}, \dot{y}, y, V r)=F_{T}-M_{f} \cdot \ddot{y}-C_{f}(V r) \cdot \dot{y}-K_{f}(V r) \cdot y \\
V_{r}=V /(f * D)
\end{gathered}
$$

Where $\ddot{y}, \dot{y}$ and $y$ are acceleration, velocity and displacement vectors. Under some specific conditions of fluid reduced velocity, $C_{f}$ is negative enough to make the structure instable. This phenomenon is called fluid-elastic instability and can damage the structure. The tubes are however supported by plates (see Fig.1) which guide them and limit their vibration amplitude. In fact, the impacts between the tubes and the plate tend to stabilize the tubes. Thus, we can finally represent the whole problem as below:

$$
\mathcal{M} \cdot \ddot{y}+\mathcal{C} \cdot \dot{y}+\mathcal{K} \cdot y=F_{t}+F_{f-e}\left(\ddot{y}, \dot{y}, y, V_{r}\right)+F_{c}
$$

Premultiplying the Eq.(2) by modal base $\Phi$ we get a set of independent equations of motion in the modal coordinates

$$
\mathcal{M}_{m} \cdot \ddot{q}+\mathcal{C}_{m} \cdot \dot{q}+\mathcal{K}_{m} \cdot q=f_{t}+f_{f-e}\left(\ddot{q}, \dot{q}, q, V_{r}\right)+f_{c}
$$

Where $\ddot{q}, \dot{q}, q$ are generalized acceleration, velocity and displacement vectors. Because these mechanisms are complex and difficult to realize in an experimental set up, the main aim of our study is to develop a hybrid control loop to simulate this coupling effect in the frame of an experimental characterization test bench.

\section{STRUCTURE \& MODAL UPDATING}

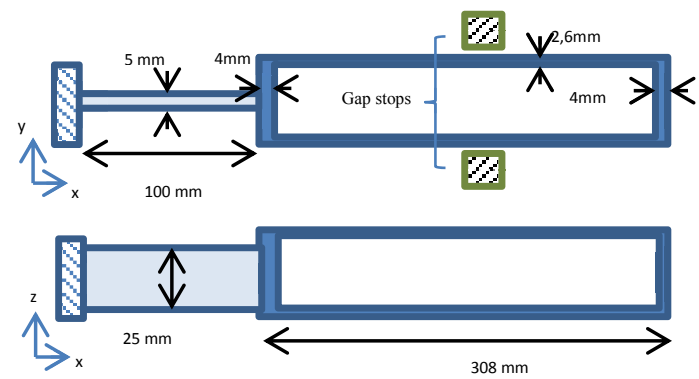

Figure 2. Gap supported tube

The studied structure Fig.2 is composed of a tube attached to a slender plate clamped in rigid block. At the middle height of the tube, two gap stops located at $0.5 \mathrm{~mm}$ create punctual impacts depending on the vibration amplitude of the tube.

A finite element shell model was developed to generate the mass, damping and stiffness matrices. This model was updated in order to match the numerical behavior with experimental one. Two criterions were used to compare the numerical and experimental model: Modal Assurance Criterion (MAC) and frequency error criterion. Fig. 3 \& Tab. 1 summarizes the results obtained for the 6 first modes.

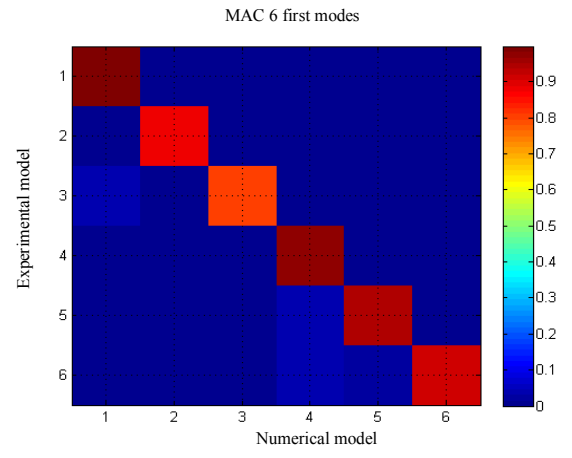

Figure 3. Modal updating (MAC)

\begin{tabular}{|c|c|c|c|}
\hline Modes & $\begin{array}{c}\text { Numerical modal } \\
\text { frequency }\end{array}$ & $\begin{array}{c}\text { Experimental modal } \\
\text { frequency }\end{array}$ & Error \\
\hline 1 & 23.1 & 23 & $0 \%$ \\
\hline 2 & 103 & 100 & $3 \%$ \\
\hline 3 & 305 & 318 & $4 \%$ \\
\hline 4 & 426 & 407 & $4.6 \%$ \\
\hline 5 & 774 & 798 & $3 \%$ \\
\hline 6 & 1300 & 1404 & $8 \%$ \\
\hline & & Mean & $3.7 \%$ \\
\hline
\end{tabular}

Tab 1. Frequency error

It can be observed that there is a good agreement between the two models. The lowest values of MAC is $85 \%$ and the mean frequency error is lower than $4 \%$. 


\section{EXPERIMENTAL IDENTIFICATION}

\section{Impact stiffness:}

The only source of nonlinearity in our problem comes from the impact forces located at $\mathrm{x}_{\mathrm{c}}$ (middle height of tube), which are computed in an explicit manner as the Eq.(4) shows.

$$
\left\{\begin{array}{lr}
F_{c}(t)=K_{c} \cdot\left(y\left(x_{c}, t\right)-g\right) & \text { if }\left|y\left(x_{c}, t\right)\right|>g \\
F_{c}(t)=0 & \text { if }\left|y\left(x_{c}, t\right)\right| \leq g
\end{array}\right.
$$

Where $K_{c}$ is the impact stiffness. The value of the parameter $\mathrm{K}_{\mathrm{c}}$ is identified through experimental measurements. Several impact tests were performed in which the impact forces where measured by using force sensor. Knowing the mass sensor , $\mathrm{M}_{\mathrm{c}}{ }^{\mathrm{ee}}$ and measuring the duration of the impact , $\mathrm{Tc}^{\mathrm{ee}}$, we can deduce an estimation of the impact stiffness using the following approximation:

$$
T c=\frac{\pi}{\omega}=\pi \sqrt{M_{c} / K}
$$

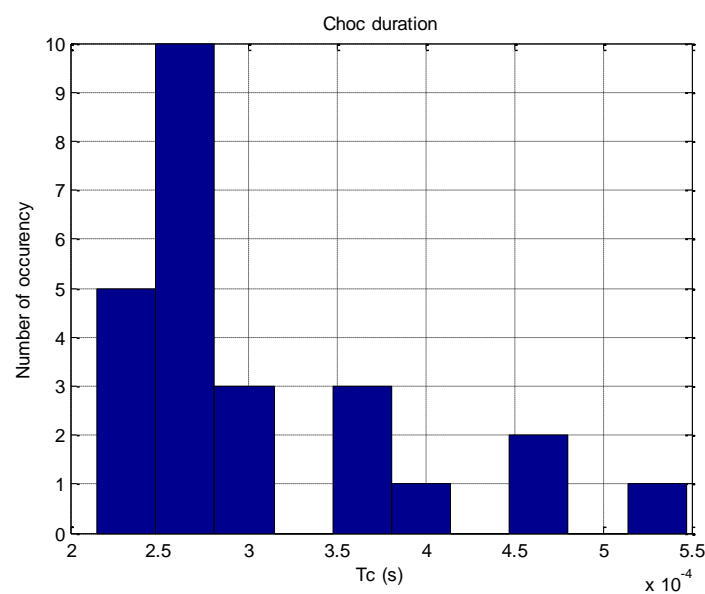

Figure 4. Impact stiffness identification

Figure 4 presents a histogram of the obtained results for 25 tests. $\mathrm{K}_{\mathrm{c}}$ was estimated at $10^{6} \mathrm{~N} / \mathrm{m}$ on average (for $\mathrm{T}_{\mathrm{c}}=0.3 \mathrm{~ms}$ on average), which matches with the results found by P.Piteau [4] \& T.Thenint[5].

\section{Fluid-elastic forces parameters:}

In order to model fluid-elastic forces, a significant research effort has been conducted over the last four decades. These researches leaded to several theoretical models. We can quote M.Paidoussis [6], S.Price [7] or S.Granger [8] models etc. In our study we have chosen the CEA one [9] which is semianalytical model. In this approach, the parameters $\mathrm{M}_{\mathrm{f}}, \mathrm{C}_{\mathrm{f}}$ and $\mathrm{K}_{\mathrm{f}}$ are identified experimentally.

Referring to works carried out by CEA [4], the first mode is predominant in the tube response and the effects of higher modes are almost negligible, thus the fluid elastic force is projected only on the first mode and the other modes are not influenced.

$$
f_{f . e}(\ddot{q}, \dot{q}, q)=-\left(m_{f} \ddot{q}+c_{f}\left(V_{r}\right) \dot{q}+k_{f}\left(V_{r}\right) q\right)
$$

Therefore, the fluid-elastic effect can be finally modeled as fluid added mass, fluid added damping and fluid added stiffness. These last two coefficients are assumed depending on reduced fluid velocity $\mathrm{V}_{\mathrm{r}}[4]$.

$$
\begin{aligned}
{\left[\begin{array}{ccc}
m_{1}+m_{f} & 0 & 0 \\
0 & m_{2} & 0 \\
0 & 0 & \ddots
\end{array}\right] \ddot{q}+\left[\begin{array}{ccc}
c_{1}+c_{f}\left(V_{r}\right) & 0 & 0 \\
0 & c_{2} & 0 \\
0 & 0 & \ddots
\end{array}\right] \dot{q} } \\
+\left[\begin{array}{ccc}
k_{1}+k_{f}\left(V_{r}\right) & 0 & 0 \\
0 & k_{2} & 0 \\
0 & 0 & \ddots
\end{array}\right] q=f_{t}+f_{c}
\end{aligned}
$$

At this stage, in order to completely identify fluid-elastic forces we should determine the three parameters $m_{f}, c_{f}\left(V_{r}\right)$ and $\mathrm{k}_{\mathrm{f}}\left(\mathrm{V}_{\mathrm{r}}\right)$. The modal characteristics of the structure are assumed to be known in the air and the fluid-added mass $m_{f}$ doesn't depend on fluid velocity. This parameter is then identified through the measurement of the frequency of the first mode in stagnant water and by comparing it to the equivalent measurement in air $\mathrm{m}_{\mathrm{f}}$. Concerning fluid added stiffness $\mathrm{k}_{\mathrm{f}}$ and damping $\mathrm{c}_{\mathrm{f}}$, we infer these coefficients by measuring for each fluid velocity first mode frequency and damping coefficient (see Eq.(6) \& Eq.(7)).

$$
\begin{gathered}
\omega=\sqrt{\frac{k_{1}+k_{f}}{m_{1}+m_{f}}} \\
\zeta=\frac{c_{1}+c_{f}}{2 \omega\left(m_{1}+m_{f}\right)}
\end{gathered}
$$

In the Fig.5 \& Fig. 6 we recall the results of measurements given by [4] for each value of fluid velocity.

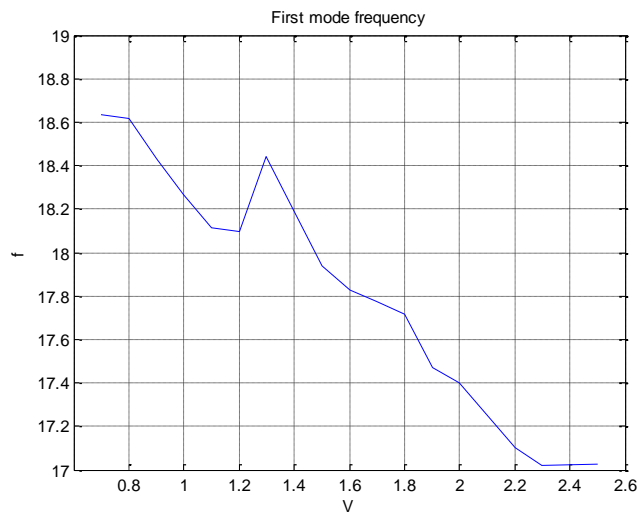

Figure 5. Identified first modal frequency depending on fluid velocity $(\mathrm{m} / \mathrm{s})$ 


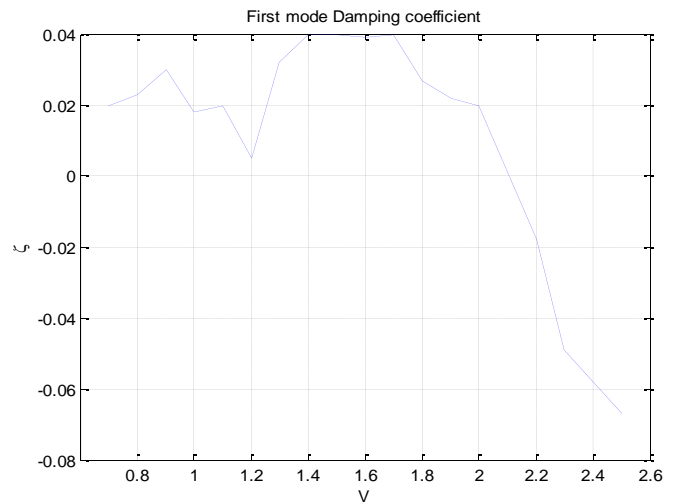

Figure 6. Identified first modal damping coefficient depending on fluid velocity $(\mathrm{m} / \mathrm{s})$

As we can notice, the damping become negative from 2.1 $\mathrm{m} / \mathrm{s}$ and the fluid elastic instability phenomenon appears. Nevertheless in non-linear case (with impacts), the structure remains stable because the gap stop limit the vibration amplitude of tube. In order to model this phenomenon, we have to introduce another dimensionless concepts, reduced velocity, coupling damping coefficient $\mathrm{C}_{\mathrm{d}}$ and coupling stiffness coefficient $\mathrm{C}_{\mathrm{k}}$. These dimensionless coefficients will help to explain the stabilizing effect of the impacts.

In his works, S.Caillaud [10] introduced the dimensionless coupling coefficient as follow:

$$
\begin{gathered}
C_{d}=8 \pi\left(m_{1}+m_{f}\right) \frac{\zeta_{o} \cdot \frac{\omega}{\omega}-\zeta}{\rho_{f} \cdot D^{2} L_{e} V_{r}} \\
C_{k}=8 \pi^{2}\left(m_{1}+m_{f}\right) \frac{\frac{\omega}{\omega}-1}{\rho_{f} \cdot D^{2} L_{e} V_{r}{ }^{2}} \\
V_{r}=V / D f \\
L_{e}=\int \varphi_{1}(x)^{2} d x
\end{gathered}
$$

Where $L_{e}$ is the modal equivalent length calculated from the first mode shape, $\zeta_{0}$ and $\omega_{0}$ are the modal damping coefficient and circular frequency in stagnant water.

When including impacts in the problem, the expression of the reduced fluid velocity in Eq.(1) becomes a little more complicated, since it depends on vibration apparent frequency of tube and not anymore on the first modal frequency (7).

There are different way to estimate this vibration tube frequency, we can quote for example zero-crossing method [11] $\&$ [12] and Rice frequency method $f_{R}$ [13]. This last method was chosen for our problem.

$f_{R}$ is proportional to velocity RMS over displacement RMS of the tube free end within sliding size windows $\tau$.

$$
f_{R}(t, \tau)=\frac{\sigma_{\dot{y}}(t, \tau)}{2 \pi \sigma_{y}(t, \tau)}
$$

The dimensionless coupling coefficients $\mathrm{C}_{\mathrm{d}}$ and $\mathrm{C}_{\mathrm{k}}$ can be inferred from $\zeta$ and $\omega$ already measured. In addition, as shown in Eq.(10) \& Eq.(11), they depend on reduced velocity. Figure 7 presents the variation of dimensionless coupling coefficient depending on reduced velocity. It can clearly be seen that $C_{d}$ become completely negative from about 3.8 .

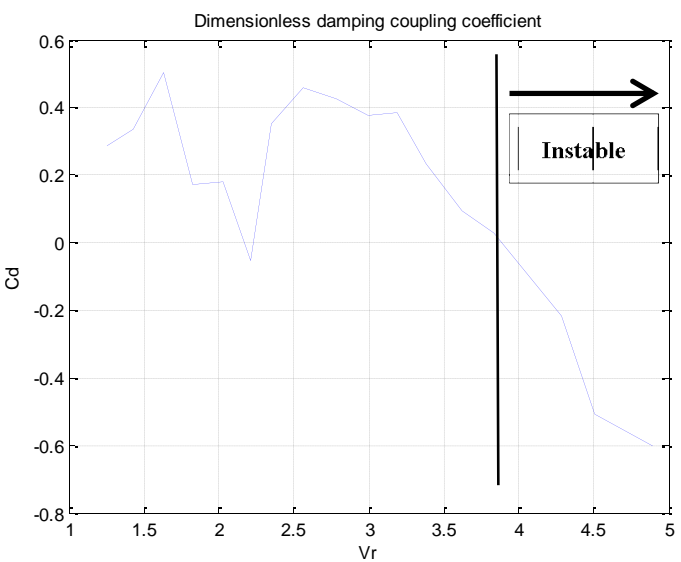

\section{Figure 7. Identified dimensionless fluid-elastic damping coupling coefficient depending on dimensionless reduced fluid velocity}

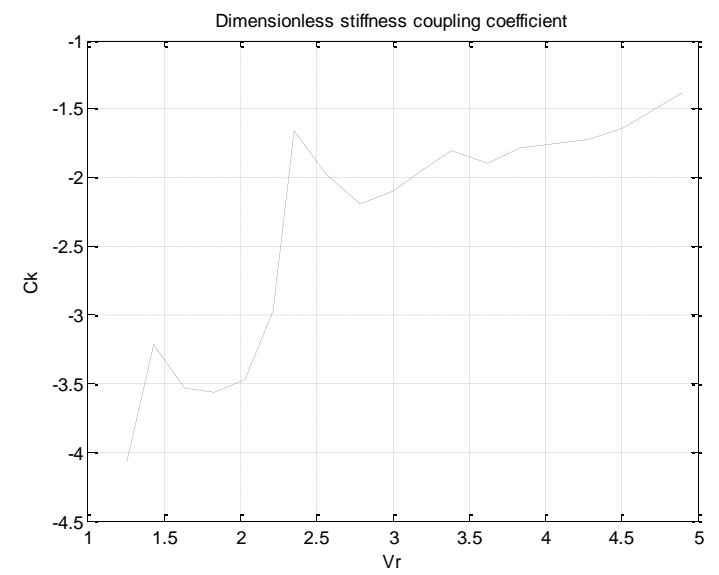

Figure 8. Identified dimensionless fluid-elastic stiffness coupling coefficient depending on dimensionless reduced fluid velocity

\section{NUMERICAL SOLVER}

After determining experimentally all parameters, the next step is to create a numerical solver including all concepts we introduced to solve the nonlinear problem. The Newmark time integration solver has been implemented to get the tube response. Numerous studies have been conducted in linear as well as in nonlinear problems[14]. 
In our approach, a mechanical conservation energy criterion has been used in order to verify trustworthiness of the numerical results. $E m$ is constituted by sum of three terms: kinetic energy, potential energy and shocks potential energy. At each computation step, theses energy are evaluated as follows and the sum is divided by the initial mechanical energy in order to get the conservation in percentage.

$$
\begin{aligned}
E c_{(n)} & =\frac{1}{2} \cdot\left(\dot{y}_{(n)}\right)^{T} \cdot \mathcal{M} \cdot\left(\dot{y}_{(n)}\right) \\
E p_{(n)} & =\frac{1}{2} \cdot\left(y_{(n)}\right)^{T} \cdot \mathcal{K} \cdot\left(y_{(n)}\right) \\
E p c_{(n)} & =\frac{1}{2 \cdot K c} \cdot\left(F c_{(n)}\right)^{T} \cdot\left(F c_{(n)}\right)
\end{aligned}
$$

First we applied this criterion on Newmark method alone without any correction algorithm taking in consideration the impacts, but it does not insure the conservation energy especially for long time simulation. To avoid this behavior, a Newton-Raphson algorithm [15] slightly modified has been implemented to in order to fit our tolerance requirement concerning the impact time. Figure 10 presents the energy conservation criterion after implementing Newton-Raphson algorithm for a computation step of $2.10^{-5} \mathrm{~s}$, we reached around $100 \%$ of energy conservation with less than $1 \%$ of error Fig. 11.

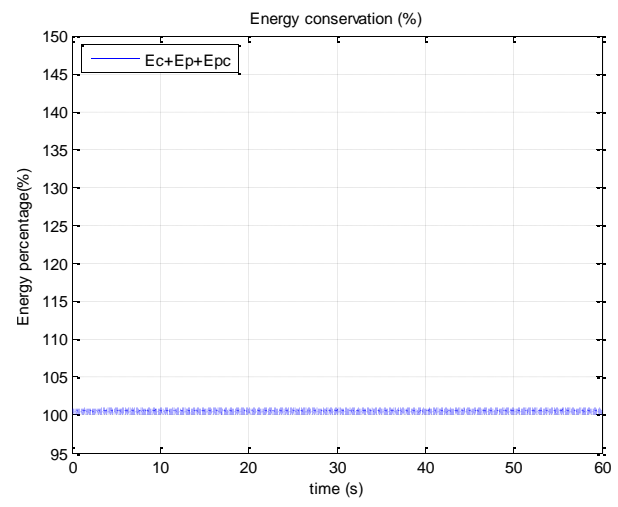

Figure 10. Newmark with Newton Raphson method conservation energy

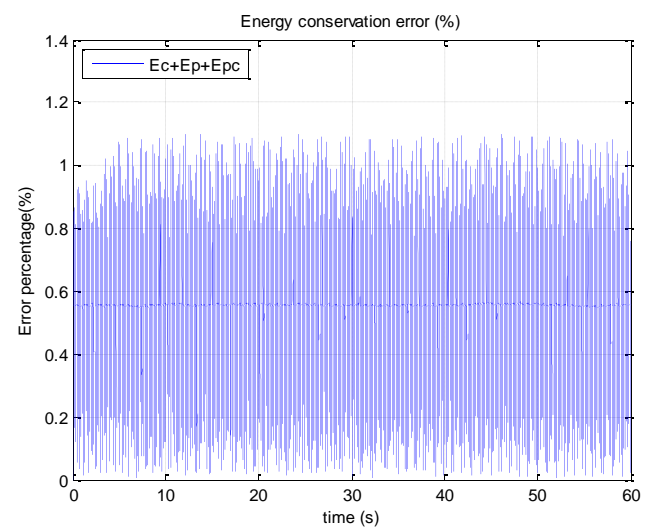

Figure 11. Newmark with Newton Raphson method conservation energy error

\section{IMPACTS STABILIZING EFFECT}

At this stage, the parameters describing the fluid elastic force are depending on reduced velocity. The later includes the effect of the impacts through apparent frequency $f_{R}$.

The impact stabilizing effect can be explained by the conjunction of two phenomena: The first one is the dissipation due to the higher orders modes of the structure. In fact, when impact occurs, many modes not excited by the turbulent flow are excited, and will then dissipate a part of energy increasing the stability of the tube. The second phenomenon is the increase of the stiffness of the structure by being in contact with a stiff obstacle. During contact, since the apparent stiffness is increased, apparent frequency of the structure should also increase, hence decreasing the reduced velocity (Eq.(12)), which makes the fluid elastic load dissipating. The numerical results in Fig.9 illustrate well this phenomenon.
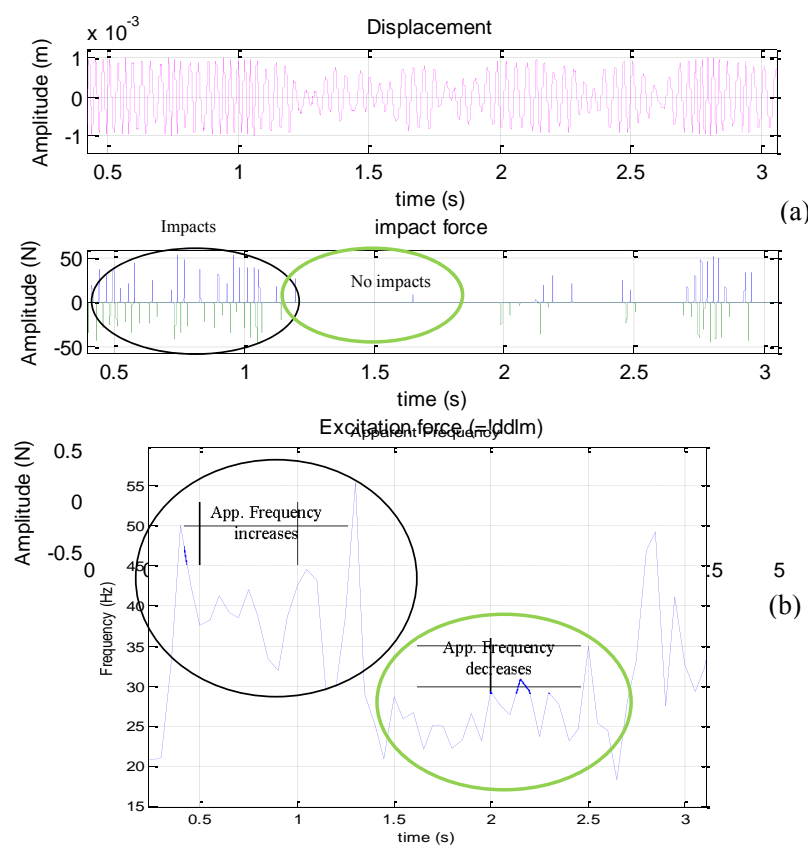

(b)

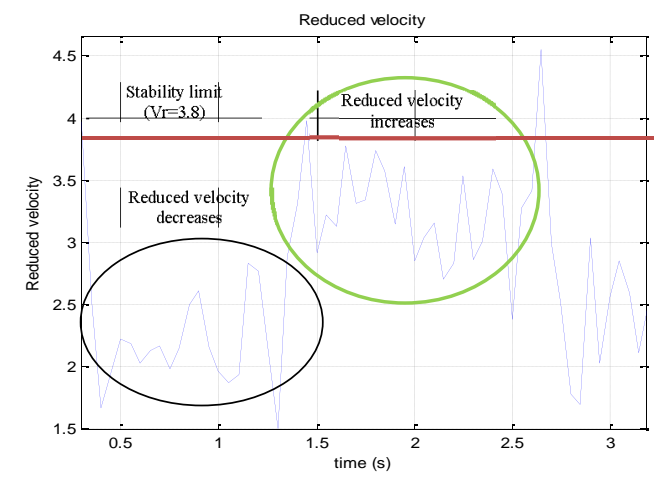

(c)

Figure 9. (a) Tube response \& estimated impact force (b) Apparent frequency (c) Reduced velocity 


\section{NUMERICAL VS EXPERIMENTAL RESULTS}

In this part we compare our first numerical results to the experimental one [9] for gap equal to $0.5 \mathrm{~mm}$ and flow velocity of $2.1 \mathrm{~m} / \mathrm{s}$ in order to validate our numerical approach. On the left side, a detailed plot of the free end displacement for numerical simulation and experimental measurement are shown. On the right, there accociated histnorame are nresented
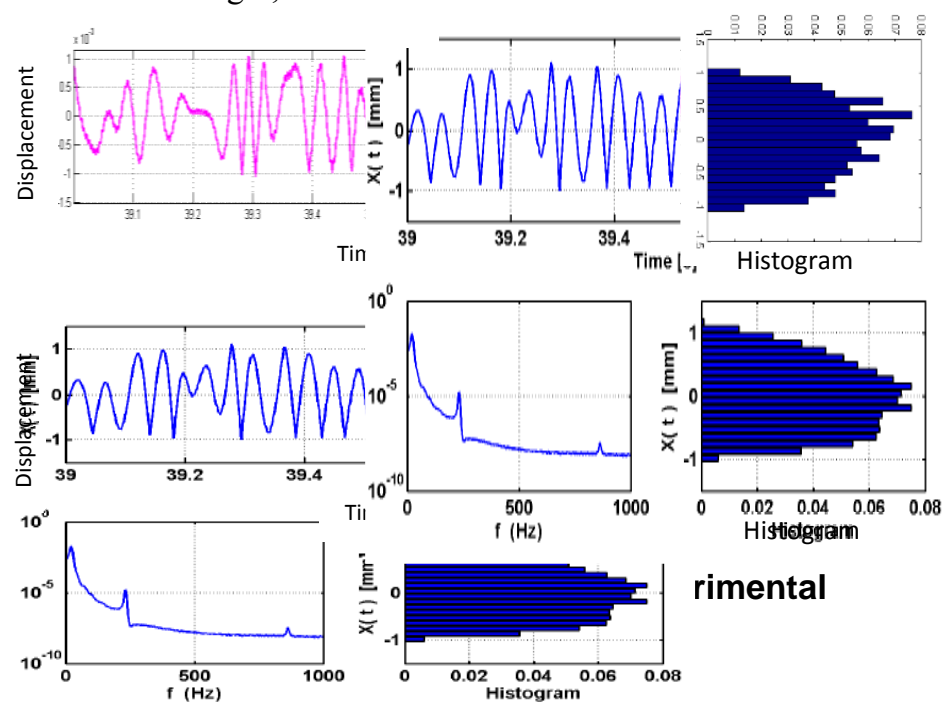

Histiesggam

rimental

appropriate and results should be compared in a statistical sense, since turbulence forces are modeled by random excitation with a bandwidth of $40 \mathrm{~Hz}$. But through this plot we can highlight the displacement which is bounded at about double distance of the gap. This can be apprehended from the first mode shape. Concerning the histogram, the distribution is centered on zero, namely the initial equilibrium position. Also notice the good agreement of the estimated time between the two results.

\section{ACTIVE CONTROL}

In order to design the active part of the bench which simulates the fluid-elastic force effect, the characterization of each control loop component (shaker, accelerometer etc) must be performed. This stage is crucial because it allows complete mastering of the system. In this paper we do not give details about this modeling stage but we can refer to Dorf and Bishop works [16] for more details.

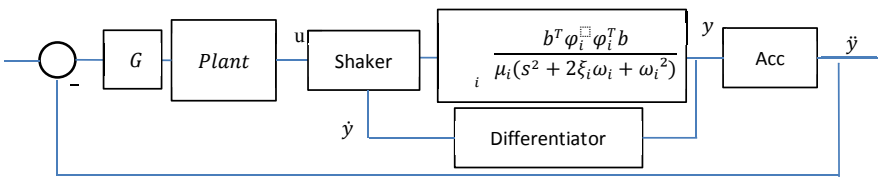

Figure 13. Control loop

After this phase of modeling, our efforts were conducted on plant designing [17]. The aim is to impose a root for first

pole (first mode) in such a way that the whole system fit as much as possible the evolution of both first modal frequency and modal damping coefficient previously measured for different value of the control gain G. In this way, by controlling the gain the corresponding reduced velocity configuration can be reproduced.

Figure 14 gives an example of a root locus of the system for a plant that we are still working on. As it can be noticed, the system becomes instable around the modal frequency of the tube in stagnant water for $\mathrm{G}=0.25$ and fluid elastic instability occurs. We are currently working on the experimental setup to validate these results before adding gap stops and studying the stabilizing effect of the impact.

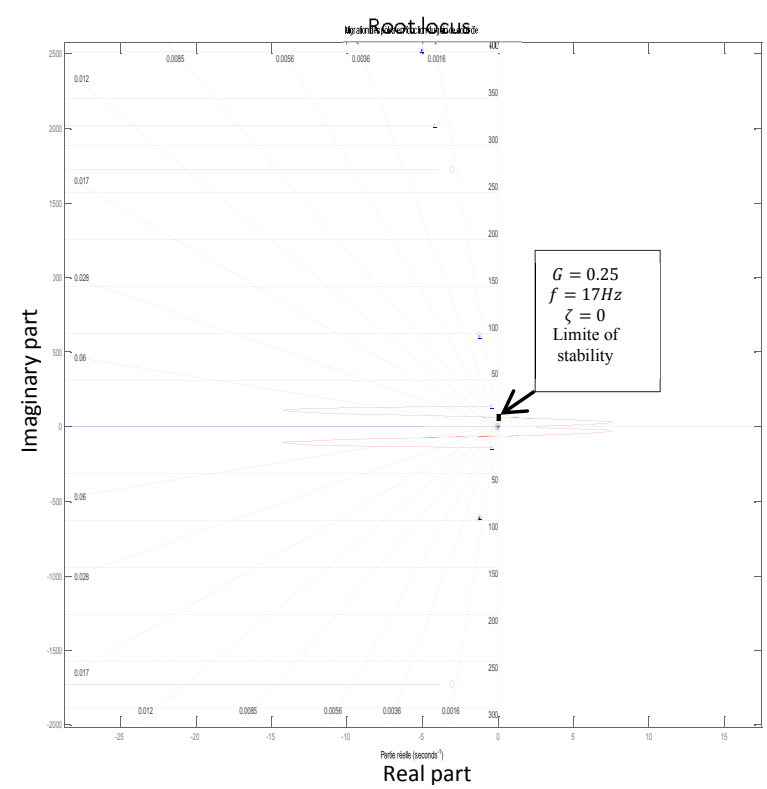

Figure 14. Root locus

\section{CONCLUSION}

A numerical model of the vibrations of a SG tube subjected to fluid-elastic and impact forces were obtained. This model was updated with experimental modal analysis results. The Newmark time integration method combined with NewtonRaphson algorithm provided an estimation of the response of the tube subjected to fluid excitation forces and impacts. The next step of our study is devoted to implementation of this controller experimentally to reproduce the fluid effect on the real structure and validate the numerical approach.

\section{REFERENCES}

[1] S. T. H. Tanaka, «Fluid elastic vibration of tube array in cross flow », Journal of Sound and Vibration, $\mathrm{n}^{\circ} 1$, p. 1937. 
[2] H. J. Connors, "Fluidelastic vibration of tube arrays excited by cross-flow », ASEMA, p. 42-46, 1970.

[3] M. Hassan et A. Hossen, "Time Domain Models for Damping-Controlled Fluidelastic Instability Forces in Tubes With Loose Supports ", in Journal of pressure vessel technology, vol. 132.

[4] P. Piteau, X. Delaune, J. Antunes, et L. Borsoi, «Experiments and computations of a loosely supported tube in a rigid bundle subjected to single-phase flow ", Journal of Fluids and Structures, vol. 28, p. 56-71, janv. 2012.

[5] T. Thénint, «Etude d'un système non-linéaire à chocs sous excitation large bande. Apllication à un tube de générateur de vapeur », Ecole Centrale de PARIS, 2011.

[6] M. P. Païdoussis, S. J. Price, et E. de Langre, FluidStructure Interactions: Cross-Flow-Induced Instabilities. Cambridge University Press, 2010.

[7] S. J. Price, "A Review of Theoretical Models for Fluidelastic Instability of Cylinder Arrays in Cross-Flow », Journal of Fluids and Structures, vol. 9, n ${ }^{\circ}$ 5, p. 463-518, juill. 1995.

[8] S. Granger, R. Campistron, et J. Lebert, «Motiondependent excitation mechanisms in a square in-line tube bundle subject to water cross-flow: an experimental modal analysis », Journal of fluids and structures, vol. 7, $\mathrm{n}^{\circ} 5$, p. 521-550.

[9] P. Piteau, X. Delaune, J. Antunes, et L. Borsoi, « VibroImpact Experiments and Computations of a GapSupported Tube Subjected to Single-Phase Fluid-Elastic Coupling Forces », 2010, p. 395-407.

[10] S. CAILLAUD, «Excitation forcée et contrôle actif pour la mesure des forces fluide-élastiques », Paris VI, 1999.

[11] B. Boashash, «Estimating and interpreting the instantaneous frequency of a signal. I. Fundamentals », Proceedings of the IEEE, vol. 80, $\mathrm{n}^{\circ}$ 4, p. 520-538, 1992.

[12] M. K. AU-YANG, «THE CROSSING FREQUENCY AS A MEASURE OF HEAT EXCHANGER SUPPORTPLATE EFFECTIVENESS », Journal of Fluids and Structures, vol. 16, n 1, p. 83-92, janv. 2002.

[13] S. O. Rice, Mathematical analysis of random noise. Bell Telephone Laboratories, 1944.

[14] M. Géradin et D. Rixen, Théorie des vibrations: application à la dynamique des structures. Masson, 1996.

[15] P. Paultre, Dynamique des structures: Application aux ouvrages de génie civil. Hermes Science Publications, 2004.

[16] R. C. Dorf et R. H. Bishop, Modern Control Systems, $12^{\mathrm{e}}$ éd. Prentice Hall, 2010.

[17] A. Preumont, Vibration Control of Active Structures: An Introduction. Springer, 2011. 